\title{
Effects of powder from white cabbage outer leaves on sponge cake quality
}

\author{
Tsvetko Prokopov ${ }^{*}$, Zhivka Goranova ${ }^{1}$, Marianna Baeva ${ }^{1}$, Anton Slavov ${ }^{1}$, and Charis M. Galanakis ${ }^{2}$ \\ ${ }^{1}$ Departments of Environmental Engineering, Nutrition and Tourism, Organic Chemistry, \\ University of Food Technologies, 26 Maritsa blvd., 4000 Plovdiv, Bulgaria \\ ${ }^{2}$ Department of Research and Innovation, Galanakis Laboratories, Skalidi 34, GR-73131 Chania, Greece
}

Received March 25, 2015; accepted August 28, 2015

A b s t r a c t. The main objective of this study was to develop high fibre cakes utilizing and valorising cabbage by-products cabbage outer leaves. Cabbage outer leaves were dried and milled in order to produce cabbage leaf powder. The cabbage leaf powder was added at $0,10,20 \%$ into sponge cake. All of the samples were subjected to physicochemical analysis and sensory evaluation. Methods of descriptive sensory analysis were used for a comparative analysis of the sponge cakes with cabbage leaf powder and the cake without cabbage leaf powder. Addition of cabbage leaf powder in sponge cakes significantly affected the cake volume and textural properties. Springiness of cakes with cabbage leaf powder and crumb tenderness were lower, while the structure was stable at high loads, as expressed by lower shrinkage in comparison with the control cake. The nutritional value of the sponge cakes with cabbage leaf powder was lower than the control cake. The cells cakes modified by cabbage leaf powder were smaller and almost equal, uniformly distributed in the crumb, and at the same time had thicker walls. The cakes with addition of cabbage leaf powder showed the springiness and their crumb tenderness were lower, while their structure was stable at high loads. Control cake showed higher water-absorbing capacity compared to the cakes with 10 and $20 \%$ cabbage leaf powder.

$\mathrm{K}$ e y w o r d s: sucrose-sweetened sponge cake, white cabbage outer leaves, waste valorization, physical characteristics, descriptive sensory analysis

\section{INTRODUCTION}

Among bakery products consumed, cakes are particularly popular and associated in the consumer mind as a delicious product (Zhang et al., 2012). The use of fruit and vegetable by-products as natural food additives has recently been suggested, due to their high content of polyphenols,

*Corresponding author e-mail: tsvetko_prokopov@abv.bg carotenoids, dietary fibre, or other bioactive compounds (Al-Sayed and Ahmed, 2013; Blasa et al., 2010; Galanakis et al., 2010; O'Shea et al., 2012). Vegetable processing industry generates significant amounts of wastes. These by-products are today considered a cheap source of valuable components since the existent technologies allow the recovery of target compounds and their use as functional additives in different products (Galanakis, 2012, 2013). The importance of food fibres has led to the development of a large and potential market for fibre products and ingredients, and nowadays there is a trend to find new sources of dietary fibre, such as food by-products that have traditionally been undervalued. On the other hand, the demand for health-oriented products that have high fibre, natural antioxidants, and low calorie contents is increasing because of their beneficial health effects (Patsioura et al., 2011; Rodríguez et al., 2006). Vegetables of the cabbage group have long been used in human nutrition due to their high nutritional value. They also have the advantage to be grown in relatively cold areas where other vegetables cannot be produced. The most important reason for the increasing interest in cabbage and cabbage by-products in the recent years is related to their protective effects against cancer (Gül et al., 2013). The main constituents of white cabbage outer leaves are carbohydrates, whereas $1 / 3$ of them are composed of dietary fibre and $2 / 3$ of low-molecular weight compounds. These leaves have an extremely low fat content, ie 1\% (Gül et al., 2013; Nilnakara et al., 2009). In addition, total radical scavenging activities of 2.4-5.4 mmol Trolox equivalents $\mathrm{g}^{-1}$ (dry weight) were reported using

(C) 2015 Institute of Agrophysics, Polish Academy of Sciences 
the DPPH assay. Nowadays, most of the outer leaves and core of cabbages (up to $40 \%$ ) are considered as wastes, which can be only used as a fertilizer or animal feed. Many investigations have demonstrated that cabbage wastes are potential sources of dietary fibre and antioxidants, which could be recovered and reutilized, adding value in different products. For instance, Jongaroontaprangsee et al. (2007) produced powder from cabbage outer leaves containing 41 to $43 \%$ of total dietary fibre (dry matter basis). On the other hand, Nilnakara et al. (2009) investigated the effects of hot-water blanching and hot air drying temperature during the production of the dietary fibre powder from the same source. They concluded that the blanched sample ried at $80^{\circ} \mathrm{C}$ could retain the highest total polyphenol content, vitamin C, and total antioxidant activity. More recently, Tanongkankit et al. (2012) investigated the effect of processing steps ie slicing, blanching, and drying, on the quality and content of glucosinolates and dietary fibres of cabbage outer leaves. Gül et al. (2013) evaluated the effects of dehydrated white cabbage by-products supplement in cookies by evaluating their chemical, physical, nutritional, and sensorial characteristics, consumers acceptance, and purchase intent. According to their outcomes, outer leaves and dried by-products of white cabbage could be utilized for preparation of cookies with improved functional and nutraceutical properties. Indeed, numerous studies have reported the addition of functional components, ie fibres, antioxidants, and oligosaccharides, in sponge cakes (Kim et al., 2012; Lu et al., 2010; Ronda et al., 2005; Santos et al., 2013).

Having in mind the above considerations, the present study aims to investigate the possibility of using cabbage wastes in sponge cake production and their effects on the technological and sensorial parameters of the baked products. For this purpose, dried and ground cabbage outer leaves were added to sponge cake flour at different proportions (10 and $20 \%)$ and the prepared bakery products were analysed for their chemical, physical, technological, and nutritional characteristics.

\section{MATERIALS AND METHODS}

Outer leaves of white cabbage (Bulgarian var. Kiose), harvested in autumn, were obtained from a local producer in Plovdiv district, Bulgaria. The cabbage leaf powder (CLP) was prepared according to the method described by Nilnakara et al. (2013). Briefly, the leaves were washed gently and chopped into the size of $0.5 \times 5 \mathrm{~cm}$. The chopped leaves were then blanched in hot water at $93 \pm 2^{\circ} \mathrm{C}$ for $2 \mathrm{~min}$, using a ratio of cabbage leaves per water equal to 1 per $7 \mathrm{~g} \mathrm{~cm}^{-3}$. Thereafter, blanched material was immediately cooled in cold water at $4^{\circ} \mathrm{C}$. Samples were dried by the convectional method in an oven at $80^{\circ} \mathrm{C}$ for $6 \mathrm{~h}$, until the moisture content decreased to $9-10 \%$. Dried samples were ground (for $2 \mathrm{~min})$ to fine powder $(<200 \mu \mathrm{m})$ using a laboratory grinder at maximum speed. Thereafter, the prepared CLP was packed in a glass container and stored in a freezer at $-18^{\circ} \mathrm{C}$ until further used.

The moisture and ash content of CLP were determined by a gravimetric method at $105^{\circ} \mathrm{C}$ and incineration at $550^{\circ} \mathrm{C}$, respectively (AOAC 1995). The total carbohydrate content was measured by the phenol-sulphuric acid method (DuBois et al., 1956). The amount of nitrogen was determined by the Kjeldahl method, following the protocol described by Kratchanova et al. (2004). A multiplication factor of 6.25 was used for the calculation of the protein content. The total, soluble and insoluble dietary fibre content of CLP was determined by the enzymaticgravimetric method, using the total dietary fibre assay kit TDF 100A (Sigma-Aldrich) and the instructions provided by the manufacturer. The total polyphenol content was determined using the Folin-Ciocalteu reagent, as described by Č́íz et al. (2010). Briefly, the dried sample ( 2 g) was transferred into extraction tubes and mixed with $20 \mathrm{~cm}^{3}$ of the $80 \%$ acetone in $0.2 \%$ formic acid. Extraction was conducted on an orbital shaker, for $1 \mathrm{~h}$ at room temperature. Thereafter, the sample was centrifuged at $6240 \mathrm{~g}$ and the supernatant was removed. The solid residue was subjected to a second extraction under the same conditions. Both supernatants were combined and further used for total polyphenol determination. Gallic acid was employed as a calibration standard. The extract obtained $\left(1 \mathrm{~cm}^{3}\right)$ or gallic acid standard solutions were mixed with $10 \mathrm{~cm}^{3}$ deionized water and $1 \mathrm{~cm}^{3}$ Folin-Ciocalteu phenol reagent. After $5 \mathrm{~min}, 2 \mathrm{~cm}^{3}$ of $20 \%$ sodium carbonate were added to the mixture. After $1 \mathrm{~h}$ in darkness, absorbance was measured at $750 \mathrm{~nm}$. The concentration of total polyphenols was expressed as gallic acid equivalents (GAE) per $100 \mathrm{~g}$ of dry weight. The antioxidant activity of CLP using DPPH and FRAP assays was determined following the protocols described by Ivanov et al. (2014). A dried sample $(0.5 \mathrm{~g})$ was extracted three times with $70 \%$ ethanol at $70^{\circ} \mathrm{C}$ in water bath for $15 \mathrm{~min}$. The mass was removed through filtration and the combined ethanol extracts were used for the next analysis. The extract obtained $\left(0.15 \mathrm{~cm}^{3}\right)$ was mixed with $2.85 \mathrm{~cm}^{3}$ of a freshly prepared $0.1 \mathrm{mM}$ solution of 1,1- diphenyl-2- picrylhydrazyl radical (DPPH, Sigma) in methanol (Merck). The reaction was performed at $37^{\circ} \mathrm{C}$ in darkness and the absorptions at $517 \mathrm{~nm}$ were recorded after $15 \mathrm{~min}$, against methanol. The antioxidant activity was expressed as mM Trolox equivalents (TE) per g dry weight (DW) using a calibration curve built by $0.05,0.1$, $0.2,0.3,0.4$, and $0.5 \mathrm{mM}$ 6-hydroxy-2,5,7,8-tetramethylchroman - 2- carboxylic acid (Trolox, Fluka) dissolved in methanol (Sigma). The FRAP reagent was freshly prepared before the analyses by mixing 10 parts of $0.3 \mathrm{M}$ acetate

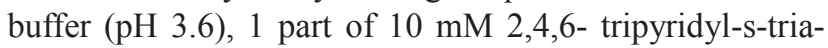
zine (TPTZ, Fluka) in $40 \mathrm{mM} \mathrm{HCl}$ (Merck), and 1 part of $20 \mathrm{mM} \mathrm{FeCl}_{3}$ (Merck) in water. The reaction was started by mixing $3.0 \mathrm{~cm}^{3}$ of FRAP reagent with $0.1 \mathrm{~cm}^{3}$ of the 
investigated extract. The blank was prepared using methanol instead of the extract. The reaction was conducted in darkness for $10 \mathrm{~min}$ at $37^{\circ} \mathrm{C}$ and the absorbance at $593 \mathrm{~nm}$ of the sample against the blank was recorded. Antioxidant activity was expressed as $\mathrm{mM} \mathrm{TE} / \mathrm{g}$ DW using a calibration curve built in a range of 0.05-0.5 $\mathrm{mM}$ Trolox (Fluka) dissolved in methanol (Merck).

Standard raw materials such as wheat flour of type 500 - ash 0.5\% (GoodMills, Bulgaria EAD), granulated sugar (Zaharni zavodi AD), eggs (local market) used in the current study are authorized by the Ministry of Health as manufactured in Bulgaria. A control cake was prepared, following a traditional technology and formulation (Angelov et al., 1974). The batter formulation of the control cake (A) was as follows (based on flour weight): egg yolk $43.23 \%$, egg white $96.77 \%$, refined granulated sugar $83.87 \%$, and wheat flour $100 \%$. In particular, a double mixing procedure was applied by partitioning the whipping of whites and egg yolks. CLP was added into the sponge cake flour to substitute $10 \%$ (B) and $20 \%$ (C) of wheat flour. Each sponge cake batter of $95 \mathrm{~g}$ was poured out in metallic forms and baked in an electric oven (Rahovetz - 02, Bulgaria) at $180^{\circ} \mathrm{C}$ for $30 \mathrm{~min}$.

The specific gravity of the sponge cake was calculated by dividing the weight of a standard batter cup with the weight of an equal volume of distilled water, at batter temperature $\left(20.7 \pm 0.5^{\circ} \mathrm{C}\right)$ (AACC Method 10-95, 1983). The physical characteristics of the sponge cakes were measured $2 \mathrm{~h}$ after baking. The volume was determined by the small uniform seed displacement method (AACC $10-05,2000$ ) and porosity was assessed according to the Bulgarian standard method (BSS 3412-79) of Yackoby (1979). The porosity $(P)$ of the sponge cake was defined as the ratio between the volume of the air-pockets in the cake crumb and the volume of the crumb. The porosity determination was done using a cylinder driller - a device of Zhuravljov, with a cylinder cut crumb (volume $27 \mathrm{~cm}^{3}$ ) at a distance of $10 \mathrm{~mm}$ from the crust. The diameter of the cylinder was $30 \mathrm{~mm}$ and the hight $-38 \mathrm{~mm}$. The formed balls $(\mathrm{d}<10 \mathrm{~mm})$ were placed in a measuring cylinder filled with mineral oil. The calculations were made using the formula:

$$
P=\frac{27-V}{27 \times 100},
$$

where: $V$ - the difference in volume between mineral oil with balls and clear mineral oil. The specific volume was expressed as the ratio between the volume of the sponge cake and its mass. The water-absorbing capacity of the sponge cake was measured by determination of biscuit swelling, according to the Bulgarian standard method BSS 15221-81. For determination of the sponge cake structure, photographs were taken of the cross sections of the half-cut cake. The indices of the structural and mechanical properties of the sponge cake crumb (shrinkage and springiness) were determined with an automatic penetrometer (model DSD VEB Feinmess, Dresden, Germany). A hemispherical body with a diameter $12.5 \mathrm{~mm}$ and total weight $300 \mathrm{~g}$ acted on the sectional surface of a sponge cake sample, $40 \mathrm{~mm}$ thick, detecting the shrinkage at the 5 and $10 \mathrm{~s}$. Relaxation was checked by means of a hemispherical body with a diameter $25 \mathrm{~mm}$ and total weight $50 \mathrm{~g}$ acting upon a $40 \mathrm{~mm}$ thick crumb cake for $5 \mathrm{~s}$. This procedure was used to determine crumb springiness (Vangelov and Karadjov, 1993). The total moisture of the samples was determined after drying the sample at $105^{\circ} \mathrm{C}$ up to a constant weight (BSS 5313-85). The $\mathrm{pH}$ of each sample was determined using a $\mathrm{pH}$ meter (model Smart PH Meter Auto Calibration Smart 0-14PH - MW102) (AACC, 1983). The ash content of the samples was determined after incineration in a muffle furnace (LM 312.11 , Germany) at $550^{\circ} \mathrm{C}$, up to a constant weight according to the Bulgarian standard method BSS 5313-85. The values of proteins, lipids, carbohydrates, dietary fibres, and reducing sugars were determined theoretically on the basis of their initial content in the raw materials enlisted in the batter composition. Carbohydrates are all that undergo metabolism in human body with the exception of dietary fibres according to Regulation No. 23/17.01.01. The energy values of sponge cakes were obtained by the Atwater and Bryant method, using the Atwater factors of 4, 9, and $4 \mathrm{kcal} \mathrm{g}^{-1}$ for protein, fat, and carbohydrate, respectively (Atwater et al., 1899). The nutritional value of $100 \mathrm{~g}$ is determined according to Regulation No. 23, from the Ministry of Health.

The descriptive test for quantitative sensory profiling was used to establish the textural sensory characteristics (shape, colour, cell size and uniformity, odour, sweetness, aftertaste, crumb tenderness) of the sponge cakes, following the ISO 6564 and ISO 6658 methods. The sponge cake samples were ready before evaluation. Samples of different cakes were kept in coded plates covered with aluminium foil. A panel of thirteen trained tasters was selected to guarantee evaluation accuracy. The intensity of each sensory characteristic was recorded on a ten-point linear scale after $1 \mathrm{~h}$ orientation sessions of the panellists, where they specified the terminology and anchor points on the scale. The coded samples were shown simultaneously and evaluated in random order among the panellists.

All experiments were performed in triplicate. The data were analysed and presented as mean values \pm standard deviation. Statistical analysis was conducted using the Statgraphics Centurion XVI Version 16.2.04 software (Statpoint Technologies Inc., USA). The analysis of variance technique, including Lavene test (ANOVA) and multiple range test, were used to determine significant differences at a $95 \%$ confidence level $(p<0.05)$. 
T a b l e 1. Chemical composition of cabbage leaf powder

\begin{tabular}{lc}
\hline Parameter & Value \\
\hline Moisture (\%) & 9.90 \\
Protein (\%) & 11.41 \\
Total lipids (\%) & 1.65 \\
Total carbohydrate (\%) & 69.20 \\
Total dietary fibres (\%) & 61.43 \\
Reducing sugars (\%) & 7.77 \\
Total ash (\%) & 7.84 \\
$\begin{array}{l}\text { Total polyphenols (mg gallic acid } \\
\text { equivalents } \mathrm{g}^{-1} \text { dry matter) }\end{array}$ & 7.5 \\
$\begin{array}{l}\text { Antioxidant activity (DPPH assay) } \\
\text { (mM Trolox equivalents g-1 dry matter) }\end{array}$ & 9.5 \\
$\begin{array}{l}\text { Antioxidant activity (FRAP assay) } \\
\text { (mM Trolox equivalents } \mathrm{g}^{-1} \text { dry matter) }\end{array}$ & 19.1 \\
\hline
\end{tabular}

*Values are determined theoretically on the basis of a sample from outer leaves of white cabbage (USDA National Nutrient Database for Standard Reference Releaseg 27 Full Report).

\section{RESULTS AND DISCUSSION}

The chemical composition of CLP used in the experiments is given in Table 1. The main component of CLP was carbohydrates $(69.2 \%)$. The lipid content is low $(1.65 \%)$ and dietary fibres predominate $(61.4 \%)$, which makes this waste material low-calorie and healthy product. The CLP has also high polyphenol content $(7.5 \mathrm{mg}$ gallic acid equivalents $\mathrm{g}^{-1}$ dry matter), which determines noticeable antioxidant capacity ( 9.5 and $15.1 \mathrm{mM} \mathrm{TE} \mathrm{g}^{-1}$ dry matter for the DPPH and FRAP assay, respectively). Gül et al. (2013) reported $20.65 \%$ total dietary fibre (dry basis) content of cabbage outer leaves, which is a relatively underestimated value in our opinion. In our research, we found the proximate TDF content of $61.43 \%$ in CLP. The difference mentioned may be due to the different cabbage varieties and drying methods used in our study.

The changes in the physico-chemical characteristics of batters and cakes containing CLP are presented in Table 2. The most accurate evaluation of the suggested technology can be achieved by comparing the qualitative characteristics of the control cake and batters containing a CLP additive. In this point of view, the sponge cake batter with CLP had higher specific gravity compared to the control cake batter. The control sponge cake had lower specific gravity and thereby a larger volume as well as greater porosity in comparison to sponge cakes with CLP. The specific gravity of cake batter is a key factor since it affects the size, texture, volume, and formation of sponge cake. For instance, air cells are incorporated into cake batter when the specific gravity is low. Contrarily, air is decreased in the cake batter when the specific gravity is high, and therefore, the volume of bakery products is decreased (Kim et al., 2012).

The data in Table 3 show that the cakes with added CLP ( $B$ and $C$ ) had a greater percentage of retained moisture than the control cake (A), which led to a difference in the indices for the structural and mechanical properties. The control cake had higher shrinkage, and the cake with 20\% CLP (C) had higher springiness than all other cakes (Table 2). An aspect that most greatly influences the moistness and soft feel of cake is the water content. Generally, the aging of cake can be reduced if the initial moisture content is high, because aging is delayed. In addition, water binding in the flour batter is influenced by the gluten protein, damaged starch, grading, lipids, oxidising agents, and moisture content (Park et al., 2008, 2009). When dietary fibre is added, water binding increases and water retention power is thereby increased. Thus, dietary fibres are recognized as an aid in delaying the aging of bakery products.

T a b l e 2. Effect of different levels of CLP on the physico-chemical characteristics of the batters and sponge cakes

\begin{tabular}{|c|c|c|c|c|}
\hline \multirow{2}{*}{$\begin{array}{l}\text { Physico-chemical } \\
\text { characteristics }^{1}\end{array}$} & \multirow{2}{*}{ Unit } & \multicolumn{3}{|c|}{ Sponge cake type } \\
\hline & & A & $\mathrm{B}$ & $\mathrm{C}$ \\
\hline Specific gravity (for batter) ${ }^{2}$ & & $0.73 \pm 0.04 \mathrm{a}$ & $0.78 \pm 0.02 b$ & $0.81 \pm 0.01 \mathrm{~b}$ \\
\hline Volume & $\mathrm{cm}^{3}$ & $250.00 \pm 7.07 \mathrm{a}$ & $211.00 \pm 15.17 b$ & $162.00 \pm 10.95 \mathrm{c}$ \\
\hline Specific volume & $\mathrm{cm}^{3} \mathrm{~g}^{-1}$ & $3.26 \pm 0.14 \mathrm{a}$ & $2.62 \pm 0.21 \mathrm{~b}$ & $2.03 \pm 0.16 \mathrm{c}$ \\
\hline Porosity & $\%$ & $64.42 \pm 1.99 \mathrm{a}$ & $60.00 \pm 1.01 \mathrm{~b}$ & $61.48 \pm 2.03 b$ \\
\hline Springiness & PU & $24.80 \pm 2.59 \mathrm{a}$ & $23.80 \pm 1.79 \mathrm{a}$ & $32.20 \pm 2.95 b$ \\
\hline Shrinkage & PU & $93.40 \pm 4.22 \mathrm{a}$ & $47.40 \pm 2.07 \mathrm{a}$ & $66.40 \pm 3.44 b$ \\
\hline Water-absorbing capacity & $\%$ & $338.80 \pm 5.17 \mathrm{a}$ & $319.20 \pm 3.90 b$ & $289.97 \pm 6.29 b$ \\
\hline
\end{tabular}

${ }^{1}$ Values are mean $\pm \mathrm{SD}(\mathrm{p}<0.05),{ }^{2}$ temperature of the batter is on the average $20.7 \pm 0.5^{\circ} \mathrm{C}$, PU - penetrometer units, a-c - values in the line with identical letters do not differ statistically significantly $(\mathrm{p}<0.05)$. 
T a b l e 3. Chemical composition and energy value of sponge cakes with added CLP (100 g product)

\begin{tabular}{|c|c|c|c|}
\hline \multirow{2}{*}{$\begin{array}{l}\text { Basic chemical composition } \\
\text { and energy value }\end{array}$} & \multicolumn{3}{|c|}{ Sponge cake type } \\
\hline & $\mathrm{A}$ & $\mathrm{B}$ & $\mathrm{C}$ \\
\hline Total moisture (\%) & $26.90 \pm 1.74 \mathrm{a}$ & $31.10 \pm 1.30 \mathrm{~b}$ & $29.37 \pm 1.54 \mathrm{~b}$ \\
\hline Protein $(\%)$ & 9.64 & 9.14 & 9.43 \\
\hline Total lipids (fat) (\%) & 5.31 & 5.02 & 5.16 \\
\hline Carbohydrate (\%) & 56.77 & 51.20 & 50.12 \\
\hline Total dietary fibres $(\%)$ & 1.17 & 3.05 & 5.12 \\
\hline Soluble dietary fibres (\%) & 0.43 & 0.98 & 1.59 \\
\hline Insoluble dietary fibres $(\%)$ & 0.74 & 2.07 & 3.53 \\
\hline $\mathrm{pH}$ (batter) & $7.60 \pm 0.05 \mathrm{a}$ & $7.10 \pm 0.01 \mathrm{~b}$ & $7.04 \pm 0.02 \mathrm{~b}$ \\
\hline $\mathrm{pH}$ & $7.71 \pm 0.35 \mathrm{a}$ & $7.07 \pm 0.01 \mathrm{~b}$ & $7.22 \pm 0.02 \mathrm{a}, \mathrm{b}$ \\
\hline Total ash $(\%)$ & $0.40 \pm 0.00 \mathrm{a}$ & $0.93 \pm 0.23 \mathrm{~b}$ & $1.33 \pm 0.23 b$ \\
\hline Energy value (kJ $100 \mathrm{~g}^{-1}$ ) & 1321.22 & 1224.44 & 1233.78 \\
\hline$\left(\mathrm{kcal} 100 \mathrm{~g}^{-1}\right)$ & 315.78 & 292.65 & 294.88 \\
\hline
\end{tabular}

$\mathrm{a}-\mathrm{b}$ - Values in the line with identical letters do not differ statistically significantly $(\mathrm{p}<0.05)$.

It was found that addition of bamboo leaf powder reduced the aging speed in yellow layer cake due to an increase in water binding by the dietary fibres. Opuntia humifusa powder is also expected to delay aging for the same reason (Kim et al., 2012).

The results of the chemical composition and the energy value of sponge sucrose-sweetened cakes are presented in Table 3. The sucrose-sweetened sponge cakes with CLP contain less proteins and fats, and they are enriched with dietary fibres. From the data presented in Table 3, it is evident that the value of dietary fibres in the sucrose-sweetened sponge cakes enriched with CLP is up to 5-fold higher than in the control cake. The fact that the content of dietary fibres in the new sponge cakes is significantly greater demonstrates that their basic origin is from the CLP. Mineral substances (expressed as the ash content) are also in greater quantity in the sponge cakes enriched with CLP than in the control cake. This fact could be attributed to the minerals contained in the CLP, proving that powders with greater ash content have a favourable effect upon human health in daily nutrition (Vasileva and Yocheva, 2007). By forming a viscous solution, soluble fibres slow down intestinal transit, delay gastric emptying, and reduce glucose and sterol absorption by the intestine. Kim et al. (2012) reported moisture values in the range of $30-32 \%$ and total fat between 7.5 and $7.9 \%$ in fibre-enriched sponge cake, while our mean values of sponge cakes with CLP were $29.37-31.10 \%$ for moisture and 5.02-5.16\% for total lipids. According to Lu et al. (2010), the mean results for the proximate composition of green tea sponge cake were in the range of $30.3-30.8 \%$ for moisture value, $7.0-8.0 \%$ for protein, $10.2-10.3 \%$ for fat, $0.9-1.2 \%$ for ash, and $50.3-$ $51.3 \%$ for carbohydrates. The mean values of protein in our sponge cakes with CLP (9.14-9.43\%) are similar to that of Lu et al. (2010), as well as ash mean values (0.93-1.33\%). The energy values to the sponge cake with CLP (between 292.65 and $294.68 \mathrm{kcal} 100 \mathrm{~g}^{-1}$ ) were also different from the values reported by Kim et al. (2012), which were in the range of 270-280 $\mathrm{kcal} 100 \mathrm{~g} \mathrm{~g}^{-1}$. Considering the chemical composition of the sucrose-sweetened sponge cakes (Table 3), it was found that the energy value of the cakes enriched with CLP was lower than that of the control cake.

During our investigations, it was found that the control cake and the cakes with CLP had a similar form, with the exception of cake B. Cake B had the smallest height (Fig. 1), and its surface had visible cracks. It was found that the crust of the control cake was softer and its crumb had higher springiness in comparison with the cake containing CLP. The crumb pores of the cakes with CLP had thicker walls, and they were larger and equal in size, which can be seen on Fig. 1. This fact corresponds with the same index of its sensor profile represented in Table 4 and Fig. 2. The springiness of cakes is a surface response of its microstructure. As a result, the springiness of the cakes with CLP and their crumb tenderness were lower, while their structure was stable at high loads. The latter observation was expressed by lower shrinkage in comparison to the control cake. The water-absorbing capacity of the 
A

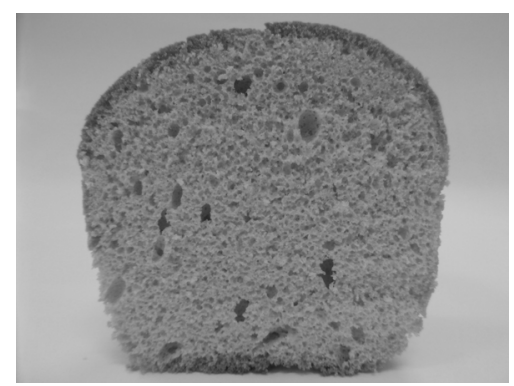

B

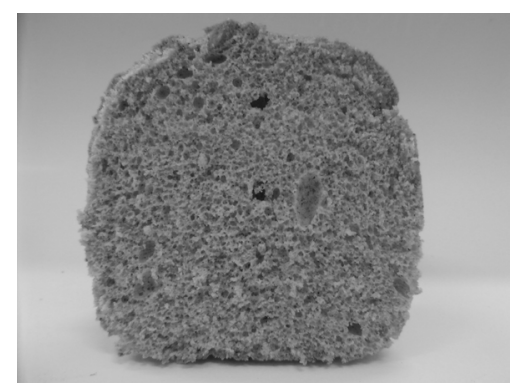

C

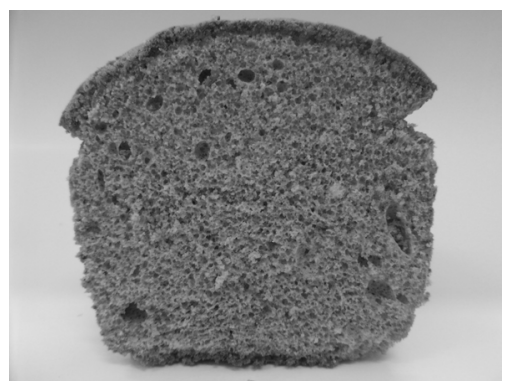

Fig. 1. The crumb structure of sliced enriched sponge cakes at different levels of CLP: A - 0\% (control cake), B - 10\%, C - 20\%.

T a b l e 4. Sensory characteristics of the sponge sucrose-sweetened cakes

\begin{tabular}{|c|c|c|c|}
\hline \multirow{2}{*}{ Sensory characteristics ${ }^{1}$} & \multicolumn{3}{|c|}{ Sponge sucrose-sweetened cake type } \\
\hline & A & $\mathrm{B}$ & $\mathrm{C}$ \\
\hline Shape & $8.38 \pm 0.96 \mathrm{a}$ & $7.31 \pm 1.97 \mathrm{~b}$ & $6.54 \pm 1.71 \mathrm{~b}$ \\
\hline Colour & $8.08 \pm 1.04 \mathrm{a}$ & $6.62 \pm 1.45 b$ & $6.69 \pm 1.32 \mathrm{~b}$ \\
\hline Cells size and uniformity ${ }^{2}$ & $7.62 \pm 1.12 \mathrm{a}$ & $6.46 \pm 1.66 \mathrm{~b}$ & $6.77 \pm 1.42 \mathrm{~b}$ \\
\hline Odour & $7.92 \pm 1.19 \mathrm{a}$ & $6.38 \pm 2.40 \mathrm{~b}$ & $6.46 \pm 2.07 \mathrm{~b}$ \\
\hline Sweetness & $6.77 \pm 1.88 \mathrm{a}$ & $5.54 \pm 2.26 \mathrm{~b}$ & $5.77 \pm 2.35 \mathrm{~b}$ \\
\hline Aftertaste & $3.46 \pm 3.48 \mathrm{a}$ & $3.62 \pm 2.99 \mathrm{a}, \mathrm{b}$ & $3.83 \pm 2.92 b$ \\
\hline Crumb tenderness & $8.31 \pm 0.75 \mathrm{a}$ & $6.92 \pm 1.66 \mathrm{~b}$ & $6.85 \pm 1.46 \mathrm{a}, \mathrm{b}$ \\
\hline
\end{tabular}

${ }^{1}$ Values are mean $\pm \mathrm{SD}(\mathrm{p}<0.05),{ }^{2}$ scale from 0 to 9 was used to evaluate sensory characteristics. Nine is ideal for the third sensory characteristic when the cells are small and equal in size. $a-b$ - Values in the line with identical letters do not differ statistically significantly $(\mathrm{p}<0.05)$.

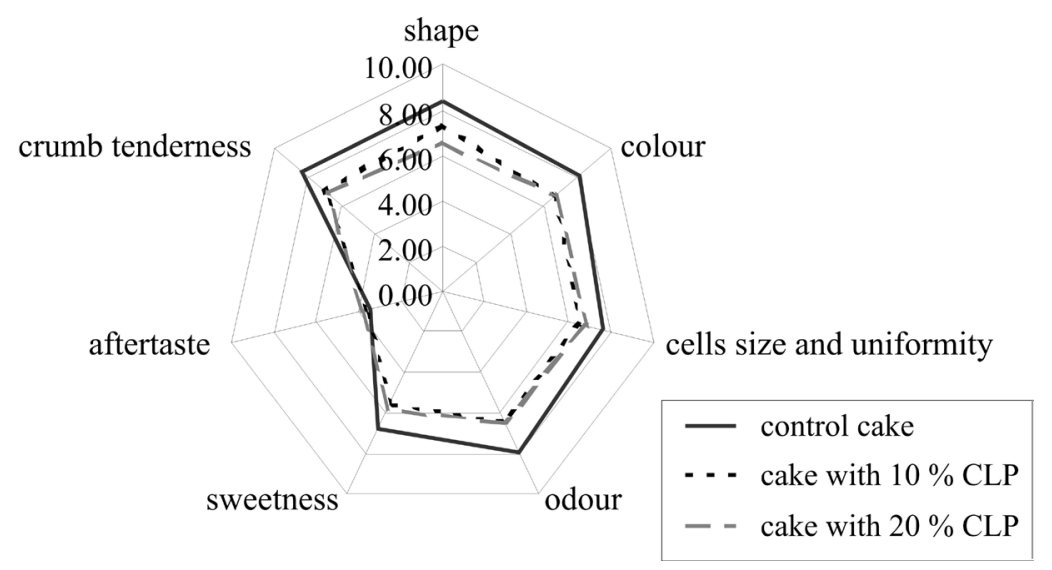

Fig. 2. Sensory profiles of sucrose-sweetened sponge cakes (A scale from 0 to 9 was used to evaluate sensory characteristics. Nine is ideal for the third sensory characteristic when the cells are small and equal in size).

cakes with CLP was lower than that of the control cake. Therefore, the cells of the control cake were smaller and almost equal, uniformly distributed in the crumb, and at the same time had thinner walls. In addition, the control cake had a crust and crumb with more pronounced light-yellow colour, due to the presence of the dyeing components in the egg yolks only (especially carotenoids). The colour of the crust and crumb of the cakes with CLP had a green brown surface and crumb with green nuance. The odour of the cakes with CLP was more strongly expressed and 
more specific towards the sample odour, and was not perceived by the sensor testers as unpleasant. The intensity of the sweetness for all investigated sponge cakes was close, but when the concentration of the CLP was greater, a bitter aftertaste was left.

\section{CONCLUSIONS}

1. The sponge cakes containing an additive of cabbage leaf powder showed satisfactory physical properties. The springiness of the cakes with cabbage leaf powder and crumb tenderness were lower, while the structure was stable at high loads, as expressed by the lower shrinkage in comparison with the control cake.

2. The nutritional value of the sponge cakes with cabbage leaf powder compared to the control cake is lower (7.90\% for cake B and $7.09 \%$ for cake C). The control cake and the cakes with cabbage leaf powder showed an approximately similar form. The crumb pores of the cakes with cabbage leaf powder had thicker, larger, and equal in size walls.

3. The properties of cabbage leaf powder changed the other sensory cakes characteristics, as the odour became more specific, the sensation for sweetness was weaker, the colour of the surface and the crumb was green-brown. The shape and the crumb tenderness were discernible, but close to those of the control cake.

4. Following the results obtained, the newly prepared products showed advanced qualitative characteristics, designed for rational and dietetic nutrition as a source of fibre.

\section{REFERENCES}

AACC, 1983. Approved method of the AACC. Method 02-52, Method 10-90, Method 44-15A, Method 44-40. American Association of Cereal Chemists. The Association, St. Paul, MN, USA.

AACC, 2000. International Method 10-05, Guidelines for Measurement of Volume by Rapeseed Displacement. Approved method of the American Association of Cereal Chemists, The Association: St. Atwater W.O., Benedict F., Bryant A., Smith A. (1899). Experiments on the metabolism of matter and energy in the human body. Washington, DC: Office of Experiment Stations Bulletin.

Al-Sayed H.M.A. and Ahmed A.R., 2013. Utilization of watermelon rinds and sharlyn melon peels as a natural source of dietary fiber and antioxidants in cake. Annals Agric. Sci., 58(1), 83-95.

Angelov L., Bekirov B., Genadieva M., Atanasov S.T., 1974. Collection- branch norms, expense norms and technological instructions in confectionaryture. Central Cooperative Union, Sofia, I, 176-183.

AOAC, 1995. Official methods of Analysis. Association of Official Analytical Chemists, Gaithersburg, MD. Paul, MN, USA.

Atwater W.O., Benedict F., Bryant A., and Smith A., 1899. Experiments on the metabolism of matter and energy in the human body. Office of Experiment Stations Bulletin, Washington, DC, USA.
Blasa M., Gennari L., Argelino D., and Ninfali P., 2010. Fruit and vegetable antioxidants in health. In: Bioactive Foods in Promoting Health. Fruits and Vegetables (Eds R.R. Watson, V.B. Preedy). Elsevier Inc. Press, San Diego, USA.

BSS 15221-81, 1981. Method for determination of water absorption ability of the biscuits

BSS 3412-79/5:1992 Bread and bakery products. Rules for sampling and testing methods.

BSS 5313-85, 1985. Physical and chemical tests. Methods for determination of dry material, moisture, ash and ash alkalinity.

Číž M., Čížová H., Denev P., Kratchanova M., Slavov A., and Lojek A., 2010. Different methods for control and comparison of the antioxidant properties of vegetables. Food Control, 21, 518-523.

DuBois M., Gilles K., Hamilton J., Rebers P., and Smith F., 1956. Colorimetric method for determination of sugars and related substances. Analytical Chemistry, 28(3), 350-356

Galanakis C.M., 2012. Recovery of high added-value components from food wastes: Conventional, emerging technologies and commercialized applications. Trends Food Sci. Technol., 26, 68-87.

Galanakis C.M., 2013. Emerging techologies for the production of nutraceuticals from agricultural by-products: A viewpoint of opportunities and challenges. Food Bioproducts Proc., 91, 575-579.

Galanakis C.M., Tornberg E., and Gekas V., 2010. Dietary fiber suspensions from olive mill wastewater as potential fat replacements in meatballs. LWT-Food Sci. Technol., 43, 1018-1025.

Gül H., Yanik A., and Acun S., 2013. Effects of white cabbage powder on cookie quality. J. Food, Agric. Environ., 11(1), $68-72$.

ISO 6564:2001. Sensory analysis. Methodology. Flavour profile methods.

ISO 6658:2005. Sensory analysis. Methodology. General guidance.

Ivanov I.G., Vrancheva R.Z., Marchev A.S., Petkova N.T., Aneva I.Y., Denev P.P., Georgiev V.G., and Pavlov A.I., 2014. Antioxidant activities and phenolic compounds in Bulgarian Fumaria species. Int. J. Curr. Icrobiol. App. Sci, 3(2), 296-306.

Jongaroontaprangsee S., Tritrong W., Chokanaporn W., Methacanon P., Devahastin S., and Chilwchan N., 2007. Effects of drying temperature and particle size on hydration properties of dietary fibre powder from lime and cabbage byproducts. Int. J. Food Prop., 10, 887-897.

Kim J.H., Lee H.J., Lee H.S., Lim E.J., Imm J.Y., and Suh H.J., 2012. Physical and sensory characteristics of fibreenriched sponge cakes made with Opuntia humifusa. LWT-Food Sci. Technol., 47(2), 478-484.

Kratchanova M., Slavov A., and Kratchanov C., 2004. Interaction of pectin with amino acids and other amino compounds in aqueous solution. Food Hydrocolloids, 18, 677-683.

Lu T.M., Lee C.C., Mau J.L., and Lin S.D., 2010. Quality and antioxidant property of green tea sponge cake. Food Chemistry, 119(3), 1090-1095. 
Nilnakara S., Chiewchan N., and Devahastin S., 2009. Production of antioxidant dietary fibre powder from cabbage outer leaves. Food Bioproducts Proc., 87, 301-307.

O'Shea N., Arendt E.K., and Gallagher E., 2012. Dietary fibre and phytochemical characteristics of fruit and vegetable by-products and their recent applications as novel ingredients in food products. Innovative Food Sci. Emerging Technol., 16, 1-10.

Park J.E., Jeong H.D., and Jang M.S., 2009. Optimization of ingredient mixing ratio for preparation of sponge cake with bamboo (Pseudosasa japonica Makino) leaves powder. Korean J. Food Cookery Sci., 25, 317-329.

Park Y.R., Han I.J., Kim M.Y., Choi S.H., Shin D.W., and Chun S.S., 2008. Quality characteristics of sponge cake prepared with red ginseng marc powder. Korean J. Food Cookery Sci., 24, 236-242.

Patsioura A., Galanakis C.M., and Gekas V., 2011. Ultrafiltration optimization for the recovery of $\beta$-glucan from oat mill waste. J. Membrane Sci., 373, 53-63.

Regulation № 23/ 2005. For physiological standards of nutrition of the population in Bulgaria. SN. n. 63/2005.

Rodríguez R., Jiménez A., Fernández-Bolaños J., Guillén R., and Heredia A., 2006. Dietary fibre from vegetable products as source of functional ingredients. Trends Food Sci. Technol., 17, 3-15.
Ronda F., Gomez M., Blanco C.A., and Caballero P.A., 2005. Effects of polyols and nondigestible oligosaccharides on the quality of sugar-free sponge cakes. Food Chemistry, 90(4), 549-555.

Santos A.C., Yassunaka N.N., Ruiz S.P., Sneider V.V., Visentainer J.V., and Madrona G.S., 2013. Sensory and physicochemical study of carrot leaf sponge cake. Revista Brasileira de Pesquisa em Alimentos, Campo Mourão (PR), 4(2), Jul./Dez.

Tanongkankit Y., Chiewchan N., and Devahastin S., 2012. Physicochemical property changes of cabbage outer leaves upon preparation into functional dietary fibre powder. Food Bioproducts Proc., 90(3), 541-548.

Vangelov A. and Karadjov G., 1993. Technology of bread and bakery products, Zemizdat, Sofia.

Vasileva R. and Yocheva L., 2007. Wholegrain foods - basic chemical composition and biologically active plant nutrients. Food Industry, 9, 44-48.

Zhang Y., Song Y., Hu X., Liao X., Ni Y., and Li Q., 2012. Effects of sugars in batter formula and baking conditions on 5-hydroxymethylfurfural and furfural formation in sponge cake models. Food Res. Int., 49(1), 439-445. 